\title{
Estimativas de parâmetros genéticos em genótipos de feijão-caupi avaliados para feijão fresco ${ }^{1}$
}

\author{
Estimation of genetic parameters in cowpea genotypes evaluated for fresh \\ southern pea
}

\author{
Fabrício Napoleão Andrade ${ }^{2}$, Maurisrael de Moura Rocha ${ }^{3 *}$, Regina Lucia Ferreira Gomes ${ }^{4}$, Francisco \\ Rodrigues Freire Filho ${ }^{3}$ e Semíramis Rabelo Ramalho Ramos ${ }^{5}$
}

\begin{abstract}
Resumo - O objetivo deste trabalho foi estimar parâmetros genéticos em caracteres associados com a produção de feijão fresco em 14 genótipos de feijão-caupi de vagem roxa e grãos brancos. Foram conduzidos três experimentos: dois sob irrigação (2004 e 2005) e um em condições de sequeiro (2005), no campo experimental da Embrapa Meio-Norte, em Teresina-PI, em delineamento de blocos completos casualizados com quatro repetições. Foram avaliados os seguintes caracteres: número de dias para a colheita de vagens frescas (NDCVF), comprimento de vagens frescas (CVF), número de grãos por vagem fresca (NGVF), peso de cem grãos frescos (P100GF), produtividade de vagens frescas (PVF), produtividade de grãos frescos (PGF), índice de grãos frescos (IGF), valor de cultivo (VC) e porte da planta (PP). As correlações genotípicas foram superiores às fenotípicas e ambientais, destacando-se as correlações entre VC e PVF (100\%). O coeficiente de variação genético variou de 6,58\% (IGF) a 31,62\% (PGF), com destaque também para PVF (30,16\%). No geral, todos os caracteres exibiram alto componente genético na expressão do caráter, com destaque para o CVF (98,72\%). Existe um alto componente genético na expressão fenotípica de todos os caracteres estudados, com grande probabilidade de ganhos genéticos em ciclos adicionais de seleção com base no fenótipo. A seleção de genótipos de feijão-caupi de alta produtividade e precoces é mais fácil do que a seleção de genótipos de alta produtividade e tardios, para o melhoramento do feijão fresco.
\end{abstract}

Palavras-chave - Vigna unguiculata. Produtividade agrícola. Variabilidade genética. Seleção.

\begin{abstract}
The aim of this work was to estimate genetic parameters in traits associated with the production of fresh southern pea in 14 cowpea genotypes of purple pod and white grains. Three experiments were carried out: two under irrigation (2004 and 2005) and one in rainfed conditions (2005), at Embrapa Mid-North experimental field, in a randomized complete block design with four replications. The correlations, genetic variation and determination coefficients were estimated for the following traits: number of days for the harvest of fresh seed (NDHFS), fresh pod length (FPL), number of seeds for fresh pod (NSFP), weight of one hundred fresh seed (WHFS), fresh pod yield (FPY), fresh seed yield (FSY), fresh seed index (FSI), value of crop (VC) and plant type (PT). The genotypic correlations were superior to phenotypic and environment correlations, being distinguished the correlations between VC and FPY (100\%). The genetic variation coefficient varied from $6.58 \%$ (FSI) to $31.62 \%$ (FSY), with highlight also for FPY (30.16\%). All characters showed high genetic component in the expression of the character, with highlight for the FPL (98.72\%). There is a high genetic component in the phenotypic expression of all the traits studied, with a high probability of genetic gains in additional cycles of selection based on phenotype. Selection of cowpea genotypes for high yield and early is easier than selection of genotypes with high yield and late in the fresh southern pea breeding.
\end{abstract}

Key words - Vigna unguiculata. Crop yield. Genetic variability. Selection.

\footnotetext{
* Autor para correspondência

${ }^{1}$ Recebido para publicação em 04/02/2009; aprovado em 16/03/2010

Pesquisa financiada pela Embrapa Meio-Norte

${ }^{2}$ Departamento de Agronomia/UFPI, Campus Agrícola da Socopo, Socopo, Teresina-PI, Brasil, 64049-550, fabricionapoleao@yahoo.com.br

${ }^{3}$ Pesquisador da Embrapa Meio-Norte, Av. Duque de Caxias, 5650, Buenos Aires, Teresina-PI, Brasil, 64006-220, mmrocha@cpamn.embrapa.br,

freire@cpamn.embrapa.br

${ }^{4}$ Departamento de Fitotecnia//UFPI, Campus Agrícola da Socopo, Socopo, Teresina-PI, Brasil, 64049-550, rlfgomes@ufpi.edu.br

${ }_{5}^{5}$ Pesquisadora da Embrapa Tabuleiros Costeiros, Av. Beira Mar, 3250, Jardins, Aracaju-SE, Brasil, semiramis@cpatc.embrapa.br
} 


\section{Introdução}

O feijão-caupi (Vigna unguiculata (L.) Walp.) possui uma grande variabilidade genética que o torna versátil, sendo usado para várias finalidades e em diversos sistemas de produção. Este pode ser comercializado como grãos secos (mercado principal), grãos imaturos (feijão fresco ou feijão verde), farinha para acarajé e sementes. $\mathrm{O}$ mercado do feijão-caupi gira em torno, principalmente da produção de grãos secos ou imaturos (ROCHA, 2009). O feijão fresco apresenta grãos com umidade entre 60 a $70 \%$ de umidade (OLIVEIRA et al., 2001). Neste ponto, o feijãocaupi é colhido e usado para o consumo ou comercializado na forma de vagem ou grãos frescos debulhados.

O consumo de feijão fresco é uma tradição no Nordeste, fazendo parte de vários pratos típicos. Após a debulha manual, o feijão fresco é consumido em ensopados, farofas e no característico baião-de-dois, prato típico onde o feijão-caupi e o arroz são cozidos juntos, desenvolvendose um terceiro sabor muito apreciado (KBATOUNIAN, 1994). Em decorrência disso, é uma importante fonte de emprego e renda em torno das grandes cidades de médio a grande porte da região e, até mesmo, em outras regiões (FREIRE FILHO et al., 2005). É uma alternativa viável para os agricultores familiares e empresariais, pois o seu mercado apresenta preços atrativos para o produtor e boas perspectivas de expansão do consumo e do processamento industrial (FREIRE FILHO et al., 2007; ROCHA, 2009).

Para a produção de feijão fresco, geralmente, são preferidas cultivares de grãos brancos ou do tipo sempreverde. Entretanto, cultivares com grãos de outras cores também têm sido usadas, como mulato, azulada e corujinha (FREIRE FILHO et al., 2002). Além disso, o comerciante prefere genótipos que sejam fáceis de debulhar e que apresentem boa conservação pós-colheita (ROCHA et al., 2006). A produtividade de vagens e grãos frescos têm sido as características mais estudadas para esse sistema de produção (OLIVEIRA et al., 2001; OLIVEIRA et al., 2003; PANDEY et al., 2006; ROCHA et al., 2007; SANTOS et al., 2007).

O estudo e a identificação de parâmetros genéticos como: coeficiente de variação genético, herdabilidade e correlação entre caracteres são de suma importância, pois através destes podemos: conhecer a variabilidade genética, o grau de expressão de um caráter de uma geração para outra e a possibilidade de ganhos por meio da seleção direta ou indireta (ROCHA et al., 2003). Informações sobre as estimativas de parâmetros genéticos quantitativos têm contribuído para aumentar a eficiência dos programas de melhoramento de feijão-caupi (SINGH, 2007).

A obtenção de estimativas de parâmetros genéticos, como correlações entre caracteres e os coeficientes de herdabilidade/determinação e variação genéticos, em estudos envolvendo o cultivo para produção de grãos secos em feijão-caupi, são comuns na literatura (BARROS et al., 2006; LOPES et al., 2001; MACHADO et al., 2008; MATOS FILHO et al., 2009; OMOIGUI et al., 2006; ROCHA et al., 2003; SANTOS; SANTOS, 2004; TEIXEIRA et al., 2007; TORRES et al., 2006; UBI et al., 2007). No entanto, estudos com esta finalidade envolvendo o cultivo do feijão-caupi para produção de grãos frescos são raros (PEKSEN, 2004; ROCHA et al., 2005).

O objetivo deste trabalho foi estimar parâmetros genéticos em 14 genótipos de feijão-caupi de vagem roxa e grãos brancos em caracteres associados com a produção de feijão fresco.

\section{Material e métodos}

Quatorze genótipos (linhagens e cultivares) de vagem roxa e grãos brancos do Banco Ativo de Germoplasma de Feijão-caupi da Embrapa Meio-Norte foram avaliados com o objetivo de se estimar parâmetros genéticos associados com a produção de feijão fresco. Foram conduzidos três experimentos, dois sob irrigação (2004 e 2005) e um em condições de sequeiro (2005), no campo experimental da Embrapa Meio-Norte, em Teresina-PI, localizado a $5^{\circ} 05^{\prime}$ de latitude Sul, $42^{\circ} 49^{\prime}$ de longitude Oeste e altitude de $72 \mathrm{~m}$.

Os experimentos foram delineados em blocos completos casualizados com quatro repetições. A parcela experimental foi representada por quatro fileiras de cinco metros, com espaçamento entre fileiras de $0,75 \mathrm{~m}$ e de $0,25 \mathrm{~m}$ entre plantas dentro da fileira. A área útil da parcela foi representada pelas duas fileiras centrais.

O plantio ocorreu entre a primeira semana de março (ensaio em condições de sequeiro) e última semana de julho (ensaios em condições irrigadas), de forma que neste período, a colheita ocorresse sempre no final das chuvas. A precipitação total registrada no período de condução do ensaio de sequeiro, no ano de 2005, foi de $816,6 \mathrm{~mm}$ (Tabela 1). Nos ensaios irrigados, adotou-se o método por aspersão, utilizando-se uma lâmina de $10 \mathrm{~mm} \mathrm{~h}^{-1}$.

Tabela 1 - Índices pluviométricos ocorridos durante o período experimental. Teresina, PI, 2004/05

\begin{tabular}{cc}
\hline Mês & Altura pluviométrica $(\mathrm{mm})$ \\
\hline Fevereiro & 236,4 \\
Março & 300,4 \\
Abril & 161,2 \\
Maio & 118,6 \\
\hline Total & 816,6 \\
\hline
\end{tabular}


A adubação foi realizada atendendo às recomendações para o solo de cada área experimental, baseada nos teores de fósforo e potássio, geralmente com aplicação de 40 a $80 \mathrm{~kg} \mathrm{ha}^{-1}$ de $\mathrm{P}_{2} \mathrm{O}_{5}$ e de 20 a $40 \mathrm{~kg} \mathrm{ha}{ }^{-1}$ de $\mathrm{K}_{2} \mathrm{O}$. O uso de adubação nitrogenada não ocorreu, tendo em vista que o feijão-caupi é uma leguminosa que se beneficia da associação simbiótica com bactérias do gênero Rhizobium. Os tratos culturais consistiram do uso de herbicida (S-Metolachlor) e capina complementar para o controle de ervas daninhas, via pulverizador costal manual. Foram aplicados inseticidas (Thiamethoxam e Dimetoato) para o controle de insetos mastigadores (vaquinhas e lagartas) e sugadores (pulgões, percevejos e trips), quando necessário, via pulverizador tratorizado de barras.

Foram determinados os coeficientes de correlações fenotípicas, genotípicas e ambientais entre os seguintes caracteres: número de dias para a colheita de vagens frescas (NDCVF), comprimento de vagens frescas (CVF), número de grãos por vagem fresca (NGVF), peso de cem grãos frescos (P100GF), produtividades de vagens frescas (PVF), produtividade de grãos frescos (PGF), índice de grãos frescos (IGF), valor de cultivo (VC) e porte da planta (PP).

Com o intuito de padronizar a maturação das vagens, quando da colheita, foi realizada uma correção de umidade das vagens frescas, segundo metodologia adotada por Andrade et al. (2005), objetivando corrigir as diferenças de maturação de vagens observadas numa mesma colheita. Para isso, de cada genótipo colhido, retirou-se uma amostra de dez vagens frescas, pesou-se e, em seguida, colocou-se de molho em água por um período de 30 minutos. Após este período, retirou-se a amostra e pesou-se novamente. Assim, foram avaliados também os seguintes caracteres: peso de 10 vagens frescas (P10VF), peso de grãos de 10 vagens frescas (PG10VF), peso de 10 vagens frescas umedecidas $(\mathrm{P} 10 \mathrm{VFu})$ e o peso de grãos de 10 vagens frescas umedecidas (PG10VFu). Com base nessas características adicionais, foram corrigidos, obtendo os seguintes caracteres: produtividade de vagens frescas corrigida $(\mathrm{PVFc})=(\mathrm{PVF} \times \mathrm{P} 10 \mathrm{VFu} / \mathrm{P} 10 \mathrm{VF})$, produtividade de grãos frescos corrigida $(\mathrm{PGFc})=(\mathrm{PGF}$ $x$ PG10VFu/PG10VF) e índice de grãos frescos corrigido $(\mathrm{IGFc})=$ PGFc/PVFc. Adotar-se-á as siglas PVF, PGF e IGF, para os pesos e índice corrigidos.

Os caracteres $\mathrm{VC}$, avaliado no início da maturidade das vagens e baseado no aspecto geral da planta, características de vagens e de grãos e no aspecto fitossanitário; PP, o porte da planta; e FDVF, a facilidade de debulha da vagem fresca, foram obtidos em escala de notas (VC: 1 = Planta sem características apropriadas ao cultivo comercial, 2 = Planta com poucas características apropriadas ao cultivo comercial, 3 = Planta com a boa parte das características adequadas ao cultivo comercial, 4 = planta com a maioria das características adequadas ao cultivo comercial e $5=$ Planta com todas as características adequadas ao cultivo comercial; PP: 1 = porte ereto, 2 $=$ porte semi-ereto, $3=$ porte semi-prostrado e $4=$ porte prostrado; FDVF: 1 = muito difícil de debulha, 2 = difícil de debulha, 3 = fácil de debulha e 4 = muito fácil de debulha). Para esses caracteres, os dados foram transformados para $\sqrt{x+0,5}$, antes da realização das analises. Os coeficientes de correlação, de variação genética e de determinação foram estimados utilizando-se o software Genes (CRUZ, 2001).

\section{Resultados e discussão}

As estimativas das correlações indicam boa concordância dos sinais entre as correlações fenotípicas e genotípicas (Tabela 2). Em geral, as correlações genotípicas apresentam valores superiores às suas correspondentes correlações fenotípicas e ambientais. Resultados semelhantes foram obtidos por Lopes et al. (2001), Rocha et al. (2003), Teixeira et al. (2007), Machado et al. (2008) e Matos Filho et al. (2009), avaliando feijão seco.

O NDCVF apresentou correlações fenotípicas e genotípicas positivas e significativas com NGVF e ainda genotípica positiva com $\mathrm{PP}$ e negativas e significativas com PVF, PGF, IGF, P100GF, VC sendo com PP negativa somente correlação fenotípica (Tabela 2), indicando que a diminuição do porte pode diminuir o NGVF e que a seleção indireta para aumento do NDCVF pode levar a ganhos negativos para PVF, PGF, IGF e P100GF.

$\mathrm{O}$ CVF apresentou correlações fenotípicas e genotípicas positivas e significativas com o NGVF (Tabela 2), isto já era esperado, uma vez que com o aumento da vagem deve ocorrer também o aumento do NGVF; este apresentou correlação fenotípica e genotípica negativa e significativa com P100GF, mostrando que a seleção para o aumento do CVF pode diminuir o P100GF. O PVF apresentou correlações fenotípicas e genotípicas negativas e significativas com NDCVF, NGVF e PP, sendo não significativa com CVF e positiva significativa para os demais caracteres (Tabela 2), indicando que o aumento do ciclo trará aumentos na PVF, mas a redução do NDCVF pode levar a ganhos negativos na PVF. No entanto, este resultado discorda daquele obtido por Peksen (2004), que estudando feijão fresco, obteve correlação fenotípica positiva significativa entre CVF e PVF.

O PGF apresentou correlação genotípica positiva com IGF, P100GF, VC e PVF e correlações negativas significativas com NDCVF, NGVF e PP (Tabela 2). Isto mostra que a seleção indireta por meio de IGF, P100GF, VC e PVF para aumentar a PGF pode ser efetiva, mas 
Tabela 2 - Estimativas dos coeficientes de correlação fenotípica $\left(\mathrm{r}_{\mathrm{F}}\right)$, genotípica $\left(\mathrm{r}_{\mathrm{G}}\right)$ e de ambiente $\left(\mathrm{r}_{\mathrm{A}}\right)$, entre os caracteres número de dias para a colheita de vagens frescas (NDCVF), comprimento de vagem fresca (CVF), número de grãos por vagem fresca (NGVF), produtividade de vagens frescas (PVF), produtividade de grãos frescos (PGF), índice de grãos frescos (IGF), peso de 100 grãos frescos (P100GF), valor de cultivo (VC) e porte da planta (PP) em 14 genótipos de feijão-caupi avaliados em três experimentos conduzidos no município de Teresina, PI, nos anos de 2004 a 2005

\begin{tabular}{|c|c|c|c|c|c|c|c|c|c|}
\hline Caráter $^{1}$ & $\mathrm{R}$ & $\mathrm{CVF}$ & NGVF & PVF & PGF & IGF & P100GF & $\mathrm{VC}$ & PP \\
\hline \multirow{3}{*}{ NDCVF } & $\bar{F}$ & $-0,16^{\mathrm{ns}}$ & $0,25^{*}$ & $-0,92 * *$ & $-0,91 * *$ & $-0,49 * *$ & $-0,80^{* *}$ & $-0,84 * *$ & $-0,80^{* *}$ \\
\hline & G & $-0,16^{\mathrm{ns}}$ & $0,25^{*}$ & $-0,96^{* *}$ & $-0,94 * *$ & $-0,55^{* *}$ & $-0,82 * *$ & $-0,89^{* *}$ & $0,90^{* *}$ \\
\hline & A & $0,01^{\mathrm{ns}}$ & $0,06^{\mathrm{ns}}$ & $-0,04^{\mathrm{ns}}$ & $0,04^{\mathrm{ns}}$ & $0,13^{\mathrm{ns}}$ & $0,09^{\text {ns }}$ & $-0,01^{\mathrm{ns}}$ & $-0,03^{\mathrm{ns}}$ \\
\hline \multirow{3}{*}{$\mathrm{CVF}$} & $\mathrm{F}$ & & $0,77^{* *}$ & $0,20^{\text {ns }}$ & $0,14^{\mathrm{ns}}$ & $-0,19^{\text {ns }}$ & $-0,17^{\mathrm{ns}}$ & $0,06^{\mathrm{ns}}$ & $0,19^{\text {ns }}$ \\
\hline & G & & $0,78^{* *}$ & $0,20^{\text {ns }}$ & $0,14^{\mathrm{ns}}$ & $-0,20^{\mathrm{ns}}$ & $-0,17^{\mathrm{ns}}$ & $0,06^{\mathrm{ns}}$ & $0,19^{\text {ns }}$ \\
\hline & A & & $0,59 * *$ & $0,29 *$ & $0,30^{*}$ & $-0,03^{\mathrm{ns}}$ & $0,08^{\mathrm{ns}}$ & $0,25^{*}$ & $-0,07^{\mathrm{ns}}$ \\
\hline \multirow{3}{*}{ NGVF } & $\mathrm{F}$ & & & $-0,27^{*}$ & $-0,27^{*}$ & $-0,12^{\mathrm{ns}}$ & $-0,68^{* *}$ & $-0,33 *$ & $0,63^{* *}$ \\
\hline & G & & & $-0,29 *$ & $-0,29 *$ & $-0,16^{\mathrm{ns}}$ & $-0,69 * *$ & $-0,34^{*}$ & $0,70^{* *}$ \\
\hline & A & & & $0,33^{*}$ & $0,38^{*}$ & $0,34^{*}$ & $-0,07^{\mathrm{ns}}$ & $0,30^{*}$ & $0,12^{\mathrm{ns}}$ \\
\hline \multirow{3}{*}{ PVF } & $\mathrm{F}$ & & & & $0,98^{* *}$ & $0,44^{*}$ & $0,78^{* *}$ & $0,93 * *$ & $-0,84^{* *}$ \\
\hline & G & & & & $0,98^{* *}$ & $0,53^{* *}$ & $0,84 * *$ & $1,00 * *$ & $-1,00^{* *}$ \\
\hline & A & & & & $0,97 * *$ & $0,16^{\mathrm{ns}}$ & $0,05^{\mathrm{ns}}$ & $0,67 * *$ & $-0,02^{\mathrm{ns}}$ \\
\hline \multirow{3}{*}{ PGF } & $\mathrm{F}$ & & & & & $0,61 * *$ & $0,77 * *$ & $0,93 * *$ & $-0,82 * *$ \\
\hline & G & & & & & $0,70 * *$ & $0,84 * *$ & $1,00 * *$ & $-0,99 * *$ \\
\hline & A & & & & & $0,32 *$ & $0,05^{\text {ns }}$ & $0,68 *$ & $0,04^{\mathrm{ns}}$ \\
\hline \multirow{3}{*}{ IGF } & F & & & & & & $0,39^{*}$ & $0,50 * *$ & $-0,41^{*}$ \\
\hline & G & & & & & & $0,43^{*}$ & $0,52 * *$ & $-0,44^{*}$ \\
\hline & A & & & & & & $0,33^{*}$ & $0,21^{\mathrm{ns}}$ & $0,19^{\text {ns }}$ \\
\hline \multirow{3}{*}{ P100GF } & $\mathrm{F}$ & & & & & & & $0,75^{* *}$ & $-0,91 * *$ \\
\hline & G & & & & & & & $0,79 * *$ & $-0,99 * *$ \\
\hline & A & & & & & & & $0,09^{\text {ns }}$ & $0,04^{\mathrm{ns}}$ \\
\hline \multirow{3}{*}{$\mathrm{VC}$} & $\mathrm{F}$ & & & & & & & & $-0,88^{* *}$ \\
\hline & G & & & & & & & & $-0,98^{* *}$ \\
\hline & A & & & & & & & & $0,07^{\mathrm{ns}}$ \\
\hline
\end{tabular}

ns: não-significativo; *, ** Significativo a 5\% e 1\%, respectivamente, pelo teste $\mathrm{t}$

deve-se ter atenção com a seleção para NDCVF, NGVF e $\mathrm{PP}$, pois pode levar a decréscimos na $\mathrm{PGF}$. Esses resultados indicam que é possível selecionar genótipos altamente produtivos e ao mesmo tempo precoces, concordando com os resultados obtidos por Matos Filho et al. (2009) e discordando dos resultados obtidos por Peksen (2004), em feijão fresco, e Machado et al. (2008), em grãos secos, que obtiveram correlações fenotípicas positivas entre a produtividade e a maturação.

No sistema de produção do feijão fresco, ao contrário do sistema de produção do feijão seco, os pequenos produtores preferem cultivares altamente produtivas, mas que tenham um longo período de produção. De acordo com os resultados obtidos, a seleção para um longo período de produção será mais difícil do que para a precocidade.

O IGF apresentou correlações fenotípicas e genotípicas positivas e significativas com PVF, PGF, P100GF e VC e negativas e significativas com NDCVF e PP (Tabela 2). Para essas correlações, os resultados são discordantes daqueles obtidos por Teixeira et al. (2007) para o índice de grãos frescos e concordantes com os resultados de Machado et al. (2008), para a correlação entre IGF x NDCVF, no entanto, estes resultados foram obtidos em estudos com grãos secos. Esse resultado sugere que é possível selecionar genótipos com alto IGF e ao mesmo tempo produtivos e precoces. 
O VC apresentou correlação fenotípica e genotípica positiva e significativa com PVF, PGF, IGF e P100GF (Tabela 2). Isso evidencia que a seleção fenotípica por meio do fenótipo pode ser utilizada com sucesso como um critério de seleção indireta, ou seja, mediante a seleção visual. O VC pode representar aumento de eficiência na seleção de genótipos superiores em PVF e PGF. As correlações de VC com NDCVF, CVF, NGVF, P100GF, PVF e PGF estão de acordo com aquelas obtidas por Lopes et al. (2001) e Rocha et al. (2003), em feijão seco e Rocha et al. (2005) em feijão fresco.

$\mathrm{O}$ coeficiente de variação genético $\left(\mathrm{CV}_{\mathrm{G}}\right)$ variou de 6,58 (IGF) a 31,62\% (PGF) (Tabela 3). As maiores estimativas para o $\mathrm{CV}_{\mathrm{G}}$ foram apresentadas pelos caracteres PVF $(30,16 \%)$ e PGF $(31,62 \%)$, indicando que entre todos os caracteres estudados, estes mostraram maior variabilidade, possibilitando a realização de seleção. Para a produtividade de grãos, os resultados são concordantes com os de Lopes et al. (2001) e Matos Filho et al. (2009) e discordantes com Machado et al. (2008), que trabalhando com grãos secos, obtiveram estimativas de 26; 23 e 13\%, respectivamente. Ubi et al. (2007) encontraram estimativas de CVG para P100GF (9,2\%) e CVF (25,9\%) em um estudo com grãos secos, respectivamente, discordante e concordante, com as estimativas obtidos neste trabalho.

$\mathrm{O}$ coeficiente de determinação genético (CVG) variou pouco, mas apresentou valores altos para todos os caracteres $(84,58$ a $98,72 \%)$ (Tabela 3$)$. Segundo Teixeira

Tabela 3 - Estimativas do coeficiente de variação genético $\left(\mathrm{CV}_{\mathrm{G}}\right)$ e coeficiente de determinação genético $\left(\mathrm{H}^{2}\right)$ relativos aos caracteres número de dias para a colheita de vagens frescas (NDCVF), comprimento de vagem fresca (CVF), número de grãos por vagem fresca (NGVF), produtividade de vagens frescas (PVF), produtividade de grãos frescos (PGF), índice de grãos frescos (IGF), peso de 100 grãos frescos (P100GF), valor de cultivo (VC) e porte da planta (PP) em 14 genótipos de feijãocaupi avaliados em três experimentos conduzidos no município de Teresina, PI, nos anos de 2004 a 2005

\begin{tabular}{ccc}
\hline Caracteres $^{1}$ & $\mathrm{CV}_{\mathrm{G}}(\%)$ & $\mathrm{H}^{2}(\%)$ \\
\hline NDCVF (dia) & 8,17 & 95,61 \\
CVF (cm) & 9,08 & 98,72 \\
NGVF & 14,00 & 96,98 \\
PVF $\left(\mathrm{kg} \mathrm{ha}^{-1}\right)$ & 30,16 & 84,58 \\
PGF $\left(\mathrm{kg} \mathrm{ha}^{-1}\right)$ & 31,62 & 85,80 \\
IGF $(\%)$ & 6,58 & 90,56 \\
P100GF $(\mathrm{g})$ & 18,78 & 94,80 \\
VC & 28,50 & 90,21 \\
PP & 24,30 & 87,18 \\
\hline
\end{tabular}

et al. (2008), as estimativas elevadas para este parâmetro podem ser devido à variabilidade genética inerente aos genótipos testados, em razão de cada um deles contribuir com uma identidade genética distinta. Altas estimativas de CVG para os componentes de produção também foram obtidas por Lopes et al. (2001), Rocha et al. (2003) e Ubi et al. (2007). Isso indica que esses caracteres apresentam alto componente genético em suas expressões fenotípicas, sugerindo que a obtenção de ganhos pode ser conseguida via seleção visual.

Os caracteres CVF e NGVF apresentaram os maiores coeficientes de determinação genéticos, 98,72 e 96,68\%, respectivamente, sendo os demais também altos. Isso possibilita aumento da produtividade através da seleção direta (Tabela 3). Os caracteres PVF e PGF apresentaram as menores estimativas para o coeficiente de determinação genético (84,58\%), no entanto, foram altas, mesmo considerando que é um caráter muito influenciado pelos fatores ambientais. Para a PGF, os resultados apresentaram magnitudes iguais àquelas obtidas por Lopes et al. (2001) e superiores àquelas encontradas por Teixeira et al. (2007), Machado et al. (2008) e Matos Filho et al. (2009), no entanto, em grãos secos.

As estimativas de parâmetros genéticos obtidas para a produtividade e seus componentes, no presente trabalho, servirão de base para a seleção visando à obtenção de ganhos no melhoramento para a produção de feijão fresco. Segundo Singh (2007), informações sobre parâmetros genéticos quantitativos contribuem para aumentar a eficiência dos programas de melhoramento de feijão-caupi.

\section{Conclusões}

1. Existe um alto componente genético na expressão fenotípica de todos os caracteres estudados, com grande probabilidade de ganhos genéticos em ciclos adicionais de seleção com base no fenótipo para o melhoramento do feijão fresco.

2. A seleção de genótipos de feijão-caupi de alta produtividade e precoces é mais fácil do que a seleção de genótipos de alta produtividade e tardios, no melhoramento para feijão fresco.

\section{Referências}

ANDRADE, F. N. et al. Potencial genético de linhagens e cultivares de feijão-caupi para produção de feijão-verde. In: ENCONTRO DE INICIAÇÃO CIENTÍFICA DA FAPEPI, Teresina, 2005. Anais...Teresina: FAPEPI, 2005. 1 CD-ROM. 
BARROS, G. A. A. et al. Estimativas de parâmetros genéticos em progênies $\mathrm{F} 7$ de feijão-caupi avaliadas em diferentes densidades de plantas. In: CONGRESSO NACIONAL DE FEIJÃO-CAUPI, 2006, Teresina. Anais eletrônicos... Teresina: Embrapa MeioNorte, 2006. Disponível em: <http://www.cpamn.embrapa.br/ congressos/conac2006/>. Acesso em: 04 dez. 2008.

CRUZ, C. D. Programa Genes: aplicativo computacional em genética e estatística. Viçosa: UFV, 2001. 648 p.

FREIRE FILHO, F. R. et al. Melhoramento genético. In: FREIRE FILHO, F. R.; LIMA, J. A. A.; RIBEIRO, V. Q. Feijãocaupi: avanços tecnológicos. Brasília: Embrapa Informação Tecnológica, 2005. p. 28-92.

FREIRE FILHO, F. R. et al. Novo gene produzindo cotilédone verde em feijão-caupi. Revista Ciência Agronômica, v. 38, n. 03, p. 286-290, 2007.

FREIRE FILHO, F. R. et al. Adaptabilidade e estabilidade da produtividade de grãos de linhagens de caupi de porte enramador. Revista Ceres, v. 49, n. 284, p. 383-393, 2002.

KBATOUNIAN, C. A. Produção de alimentos para consumo doméstico no Paraná: caracterização e culturas alternativas. Londrina: IAPAR, 1994. 155 p. (Circular, 81).

LOPES, A. C. A. et al. Variabilidade entre caracteres agronômicos em caupi (Vigna unguiculata (L.) Walp.). Pesquisa Agropecuária Brasileira, v. 36, n. 03, p. 515-520, 2001.

MACHADO, C. F. et al. Identificação de genótipos de feijão-caupi quanto à precocidade, arquitetura da planta e produtividade de grãos. Revista Ciência Agronômica, v. 39, n. 01, p. 114-123, 2008.

MATOS FILHO, C. H. A. et al. Potencial produtivo de progênies de feijão-caupi com arquitetura ereta de planta. Ciência Rural, v. 39, n. 02, p. 348-354, 2009.

OLIVEIRA, A. P. et al. Rendimento de feijão-caupi cultivado com esterco bovino e adubo mineral. Horticultura Brasileira, v. 19, n. 01, p.81-84, 2001.

OLIVEIRA, A. P. et al. Rendimento de feijão-caupi em função de doses e formas de aplicação de nitrogênio. Horticultura Brasileira, v. 21, n. 01, p. 77-80, 2003.

OMOIGUI, L. O. et al. Genetic variability and heritability studies of some reproductive traits in cowpea. African Journal of Biotechnology, v. 15, n. 03, p. 1191-1195, 2006.

PANDEY, I. R. et al. Evaluation of vegetable type cowpea varieties for commercial production in the river basin and low hill areas. Nepal Agricultural Research, v. 07, n. 01, p. 16-20, 2006.
PEKSEN, A. Fresh pod yield and some pod characteristics of cowpea (Vigna unguiculata L. Walp.) genotypes from Turkey. Asian Journal of Plant Science, v. 03, n. 03, p. 269-293, 2004.

ROCHA, M. de M. O feijão-caupi para consumo na forma de feijão fresco. 2009. Disponível em: $<$ http://agrosoft.com/pdf. php/?node=212374> . Acesso em: 31 jan. 2010.

ROCHA, M. M. et al. Correlações fenotípicas entre caracteres associados com a produção de feijão-verde em feijão-caupi. In: SIMPOSIO DE RECURSOS GENETICOS PARA A AMERICA LATINA Y EL CARIBE, 5., 2005, Montevideo, Anais... Montivideo: INIA: Facultad de Agronomia CIRG, 2005. p. 80.

ROCHA, M. M. et al. Estimativas de parâmetros genéticos em genótipos de feijão-caupi de tegumento branco. Revista Científica Rural, v. 08, n. 01, p. 135-141, 2003.

ROCHA, M. M. et al. Avaliação agronômica de genótipos de feijão-caupi para produção de grãos verdes. Teresina: Embrapa Meio-Norte. 2006. 16 p. (Boletim de Pesquisa e Desenvolvimento, 67).

ROCHA, M. M. et al. Avaliação preliminar de genótipos de feijão-caupi para feijão-verde. Revista Científica Rural, v. 12, n. 01, p. 153-156, 2007.

SANTOS, J. F. et al. Produtividade do feijão-caupi utilizando biofertilizante e uréia. Tecnologia e Ciência Agropecuária, v. 01, n. 01, p. 25-29, 2007.

SANTOS, C. A. F.; SANTOS, G. M. Correlações fenotípicas em dois cruzamentos de feijão-caupi nas gerações $F_{1}, F_{2}, F_{3}, F_{4}$ e $F_{5}$. Horticultura Brasileira, v. 02, n. 02, 2004. Suplemento. 1 CD-ROM.

SINGH, B. B. Recent Progress in cowpea genetics and breeding. Acta Horticulture, v. 752, n. 13, p. 69-75, 2007.

TEIXEIRA, N. J. P. et al. Produção, componentes de produção e suas inter-relações em genótipos de feijão-caupi (Vigna unguiculata (L.) Walp.) de porte ereto. Revista Ceres, v. 54, n. 314, p. 374-382, 2007.

TORRES, F. E. et al. Estimativas de parâmetros genéticos em linhagens de porte prostrado avaliadas em Aquidauana, MS. In: CONGRESSO NACIONAL DE FEIJÃO-CAUPI, 2006, Teresina. Anais eletrônicos... Teresina: Embrapa MeioNorte, 2006. Disponível em: <http://www.cpamn.embrapa.br/ congressos/conac2006/>. Acesso em: $04 \mathrm{dez} .2008$.

UBI, B. E.; MIGNOUNA, H.; OBIGBESAN, G. Segregation for seed Wight, pod lenght and days to flowering following a cowpea cross. African Crop Science Journal, v. 09, n. 03, p. $463-470,2007$. 